\title{
Pengaruh Penyuluhan Ibu Hamil Terhadap Pemberian Asi Ekslusif
}

\section{Sari Puspita Melia ${ }^{1}$, Febi Ratnasari ${ }^{2 *}$}

${ }^{1}$ Program S1 Keperawatan STIKes Yatsi Tangerang, JL. Aria Santika, Margasari Kec. Karawaci Kota Tangerang

${ }^{2}$ Program S1 Keperawatan STIKes Yatsi Tangerang, JL. Aria Santika, Margasari Kec. Karawaci Kota Tangerang

Korespodensi: Sarumeliapuspita@gmail.com

\begin{abstract}
Abstrak: Cakupan pemberian ASI di Indonesia pada tahun 2015 hanya sebesar 55,7\% dan jika mengacu pada target renstra di tahun 2015 yang sebesar 39\% maka secara nasional cakupan pemberian ASI ekslusif pada bayi usia kurang dari 0 sampai 6 bulan telah memenuhi target. Presentase pemberian ASI Ekslusif pada usia bayi 0-6 bulan di Provinsi Banten pada tahun 2016 sebesar 61,6\%, sedikit meningkat jika dibandingkan dengan presentase pemberian ASI ekslusif pada tahun 2015 yaitu hanya sebesar 60,7\%. Kabupaten/Kota dengan presentase pemberian ASI ekslusif terendah adalah Kabupaten Pandeglang yaitu 19,88\%, diikuti dengan Kota Serang sebesar 39,77\% (Profil Kesehatan Indonesia, 2018). Akibat dari tidak diberikannya asi ekslusif akan berdampak kepada kesehatan bayi antara lain angka kejadian diare, infeksi dan kekurangan gizi. Metode analisis yang digunakan ialah metode analisis isi jurnal. Jurnal yang dapat dibaca harus dibaca dan dicermati supaya jelas dalam menganalisis jurnal-jurnal tersebut. Dan dibuat analisa mengenai isi yang didapat dari tujuan penelitian dan hasil penelitian tersebut. Penelusuran literatur riview ini melalui situs jurnal yang sudah terakreditasi yaitu google schoolar, PubMed dan menggunakan literatur dari tahun 20162020. Hasil yang didapatkan 67 jurnal menggunakan kata kunci dan dan disaring lagi berdasarkan kriteria inklusi dan didapatkan hasil literatur yang memenuhi syarat sebanyak 20 jurnal. Dengan demikian dapat disimpulkan bahwa ada pengaruh penyuluhan terhadap ibu hamil tentang pemberian asi kolostrum.
\end{abstract}

Kata kunci: pengaruh penyuluhan, asi ekslusif dan exclusive breastfeeding

\begin{abstract}
Coverage of breastfeeding in Indonesia in 2015 was only 55.7\% and when referring to the 2015 strategic plan target of 39\%, nationally the scope of exclusive breastfeeding for infants aged less than 0 to 6 months has met the target. The percentage of exclusive breastfeeding in infants aged 0-6 months in Banten Province in 2016 was 61.6\%, a slight increase compared to the percentage of exclusive breastfeeding in 2015 which was only $60.7 \%$. The regency / city with the lowest percentage of exclusive breastfeeding was Pandeglang, which was $19.88 \%$, followed by Serang City at $39.77 \%$ (Indonesian Health Profile, 2018). As a result of not providing exclusive breast milk will have an impact on infant health including the incidence of diarrhea, infection and malnutrition. The analytical method used is the method of analysis of journal contents. Readable journals must be read and examined to be clear in analyzing these journals. And an analysis is made of the contents obtained from the research objectives and the results of the research. Searching this literature review through an accredited journal site namely google schoolar, PubMed and using literature from 2016-2020. Results are 67 journals were obtained using keywords and filtered again based on inclusion criteria and obtained literature results that met the requirements of 20 journals. Thus it can be concluded that there is an effect of counseling on pregnant women regarding the administration of colostrum breast milk.
\end{abstract}

Keywords: influence of counseling, exclusive breastfeeding and exclusive breastfeeding 


\section{PENDAHULUAN}

Seluruh bagian dunia tingkat pemberian ASI ekslusif sangat bervariasi. Tingkat kemajuan suatu negara tidak dapat membawa dampak yang diharapkan dalam hal keberhasilan pemberian ASI ekslusif. Pada negaranegara yang sudah maju seperti Swedia cakupan pemberian ASI ekslusif sebesar 80,2\% pada bayi berumur 6 bulan, sedangkan di Jepang hanya sebesar 44,8\% pada kelompok bayi berumur 1-2 bulan. Cina dengan negara tingkat pertumbuhan yang tinggi angka pemberian ASI ekslusif hanya sebesar 28\%, sedangkan India sebesar $46 \%$. Pada sisi lainnya, tingkat pemberian ASI ekslusif di Tunisia turun drastis dari $46,5 \%$ ditahun 2000 menjadi hanya 6,2\% pada akhir dekade ini. Di negara Afrika seperti Nigeria tidak ditemui perbaikan selama bertahun-tahun, dan beberapa angka terendah pemberian ASI ekslusif di dunia adalah di Somalia, Chad dan Afrika Selatan (UNICEF, 2013). Menurut provinsi, cakupan pemberian ASI Ekslusif di umur bayi 0-6 bulan antara 26,3\% (Sulawesi Utara) sampai 86,9\% (Nusa Tenggara Barat). Dari 33 Provinsi yang melapor, sebanyak 29 di antaranya (88\%) berhasil mencapai target renstra 2015(Kemenkes, 2016). Sedangkan di tahun 2016 di Indonesia jumlah presentasi bayi yang mendapatkan ASI Ekslusif sampai berusia 6 bulan sebesar 29,5\% (Kemenkes RI, 2017).

Presentase pemberian ASI Ekslusif pada usia bayi 0-6 bulan di Provinsi Banten pada tahun 2016 sebesar $61,6 \%$, sedikit meningkat jika dibandingkan dengan presentase pemberian ASI ekslusif pada tahun 2015 yaitu hanya sebesar 60,7\%. Kabupaten dengan presentase pemberiaan ASI ekslusif yang tertinggi adalah Kabupaten Tangerang yaitu sebesar 73,03\% dan diikuti dengan Kota Tangerang Selatan yaitu sebesar $67,91 \%$ dan Kota Tangerang yaitu sebesar $64,40 \%$. Kabupaten/Kota dengan presentase pemberian ASI ekslusif terendah adalah Kabupaten Pandeglang yaitu 19,88\%, diikuti dengan Kota Serang sebesar 39,77\%, dan Lebak sebesar 40,28\% (Profil Kesehatan Indonesia, 2018).

Bayi yang tidak mendapatkan asi ekslusif akan mengalami infeksi dan menderita gizi yang kurang menurut Yustianingrum \& Adriani (2017) infeksi pada anak balita yang diberikan ASI eksklusif yaitu sebanyak $27,3 \%$ dan non ASI eksklusif yaitu sebanyak $81,8 \%$. Sedangkan status gizi kurang berdasarkan $\mathrm{BB} / \mathrm{U}$ yakni dari 22 bayi yang mendapatkan asi ekslusif hanya 1 atau (4,5\%) anak balita yang menderita gizi kurang sedangkan dari 22 anak balita yang mendapatkan ASI non eksklusif hanya 13 atau (59,1\%) anak yang gizi nya mencukupi, sedangkan 9 anak balita non ASI eksklusif atau (40,9\%) menderita gizi yang kurang. Sebanyak 3 juta anak diantarannya meninggal setiap tahun karna kekurangan gizi. Menurut data WHO angka kematian bayi di dunia 54 per kelahiran hidup, sedangkan angka kematian bayi yang cukup tinggi di dunia pada tahun 2014 yaitu sebanyak 35 per 1000 kelahiran hidup sariana (2012). Sehingga peneliti tertarik untuk melakukan penelitian tentang pengaruh penyuluhan ibu hamil terhadap pemberian asi ekslusif

\section{METODE}

Metode pengumpulan data yang digunakan dalam penelitian ini adalah dengan menggunakan metode analisis. metode analisis yang digunakan ialah metode analisis isi jurnal. Jurnal yang dapat dibaca harus dibaca dan dicermati supaya jelas dalam menganalisis jurnal-jurnal tersebut.

Data-data yang digunakan dalam penelitian ini didapatkan dari jurnal dan hasil karya ilmiah lainnya. Lalu diperoleh hasil jurnal sebanyak 67 jurnal. Yang berasal dari PubMed 5 jurnal dan 62 jurnal berasal dari schoolar. Jurnal yang tidak dapat diakses sebanyak 3 buah jurnal karena jurnal berbayar, lalu 20 jurnal yang tidak diproses kembali karena jurnal yang didapatkan tidak lengkap seperti hanya abstraknya saja. Kemudian dilakukan pemilihan agar isi jurnal yang kita cari sesuai dengan yang kita harapkan, dengan memperhatikan kesesuaian isi, melalui pembacaan secara detail pada abstrak, metode, kesimpulan, serta statement atau kalimat-kalimat penting yang terdapat pada abstrak dan pendahuluan pada jurnal, ditambah dengan memperhatikan kondisi jurnal, seperti jurnal yang tidak bisa dibuka, jurnal yang tidak bisa didownload, jurnal yang tidak lengkap yang hanya memiliki abstrak. Sehingga setelah dilakukan skrinning didapatkan hasil jurnal sebanyak 44 jurnal, lalu dari 44 jurnal tersebut diakukan pemilihan kembali dengan menganalisis isi dari hasil penelitian didapatkan hasil 29 jurnal yang diproses kembali dan yang tidak diproses kembali sebanyak 15 jurnal karena tahunnya tidak memenuhi kriteria, dan hasil akhir dari 
pemilihan jurnal didapatkan jurnal sebanyak 20 jurnal yang sesuai dengan kriteria inklusi. Adapun kriterianya yaitu:

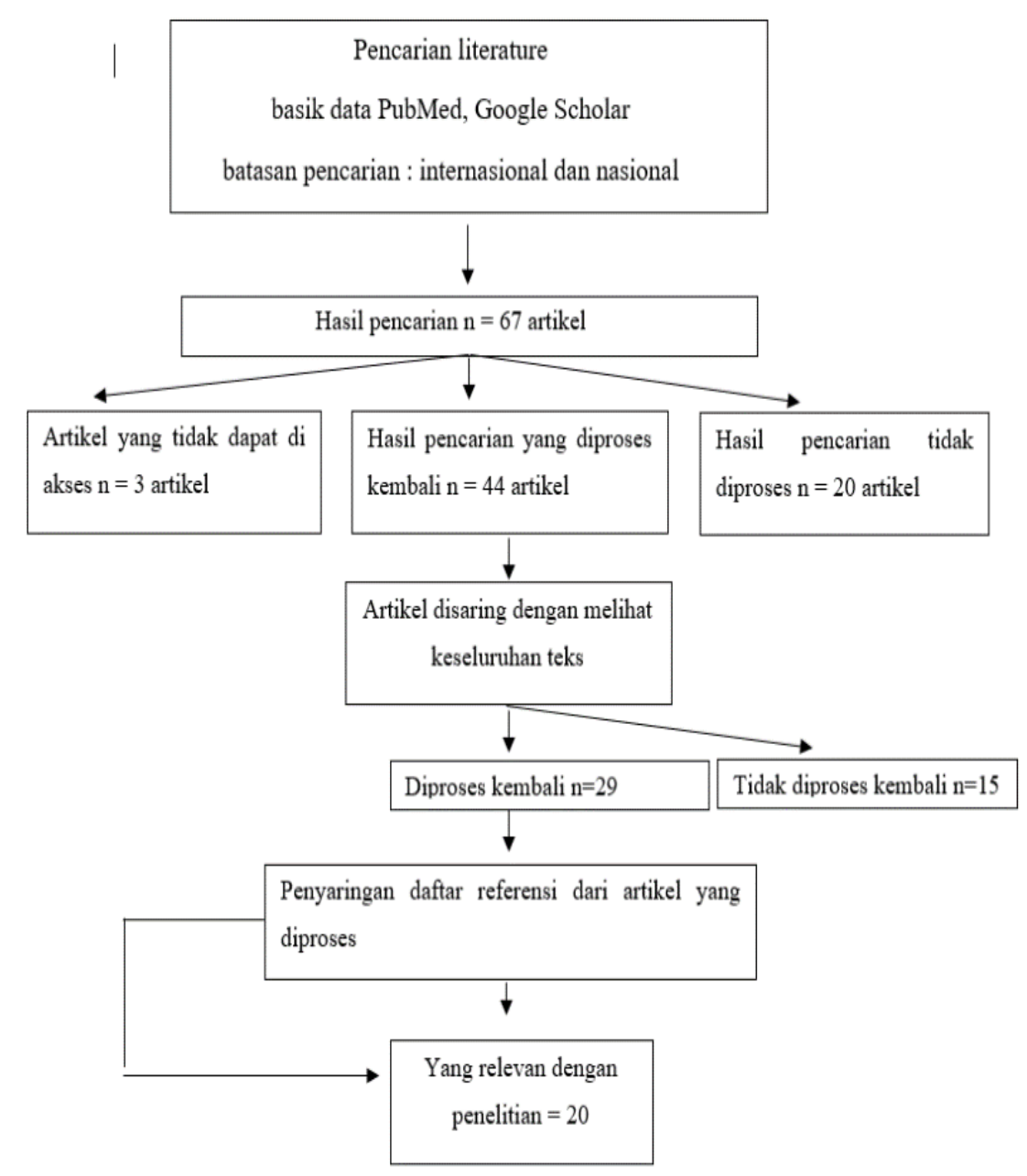

\section{PEMBAHASAN}

Berdasarkan beberapa jurnal yang diriview didapatkan bahwa penyuluhan kepada ibu hamil terhadap pemberian asi ekslusif terdapat pengaruh. Hal ini sesuai sesuai dengan pembahasan jurnal Sedangkan penelitian menurut (pohan, 2019) pengetahuan yang dimiliki oleh ibu dipengaruhi juga oleh faktor pendidikan. Jika semakin banyak informasi yang didapatkan maka pengetahuan seseorang juga semakin meningkat dan peluang seseorang dalam memberikan asi ekslusif juga semakin terbuka. Peyuluhan penelitian (Merdhika et al., 2014) bahwa ibu yang diberikan penyuluhan dengan menggunakan metode buku saku dan menggunakan metode simulasi serta yang tidak diberi metode apapun terdapat perbedaan yang signifikan yaitu, ibu yang diberikan penyuluhan dengan menggunakan metode simulasi lebih tinggi pengaruhnya jika dibandingkan dengan ibu yang diberikan dengan metode buku saku dan tidak ada metode. Pendapat (Baiduri \& Karnasih, 2018) mengatakan bahwa proses yang diberikan selama konseling kepada suami istri dapat meningkatkan peran pada masing-masing pasangan, hal ini karena pada saat couple konseling yang diberikan kepada istri oleh suaminya yaitu dukungan yang besar yang dapat berpengaruh untuk mengubah prilaku ibu menyusui yang awalnya kurang dalam memberikan asi menjadi lebih optimal dalam pemberian asi ekslusif.

Peran tenaga kesehatan dalam pemberian asi ekslusif cukup signifikan karena ikut terlibat didalam program promosi kesehatan khususnya didalam pemberian asi ekslusif (Purwanti, 2011). Sejalan dengan penelitian (Windari, dkk 2017) ibu yang telah mendapatkan dukungan dari tenaga kesehatan mempunyai peluang untuk memberikan asi ekslusifnya lebih besar dibandingkan dengan ibu yang tidak mendapatkan dukungan sama sekali oleh tenaga kesehatan. 


\section{KESIMPULAN}

Tinjauan pustaka dari berbaga jurnal didpatkan kesimpulan bahwa pengaruh ini berasal dari berbagai macam metode penyuluhan yaitu dengan menggunakan metode flip chart, metode leaflet dan metode buku saku. Lalu terdapat faktor yang mempengaruhi lainnya yaitu dengan menggunkan metode couple counseling dan juga dengan pendekatan yang dilakukan oleh tenaga kesehatan.

\section{DAFTAR PUSTAKA}

Aminah. (2012). Tingkat Pengetahuan Ibu Nifas 0-3 Hari Tentang colostrum Di Rumah Sakit Muhammadiyah Ponorogo (pp. 1-8).

Apriliana, A., Kuswanto, K., \& Runjati, R. (2017). Pengaruh Pendidikan Kesehatan Dengan Metode Ceramah Terhadap Pengetahuan Dan Sikap Pemberian Asi Eksklusif Pada Ibu Hamil Primigravida Di Puskesmas Kapuan Tahun 2016. Jurnal Kebidanan, 6(13), 26. https://doi.org/10.31983/jkb.v6i13.2871

Baiduri, A., \& Karnasih, I. G. A. (2018). Pengaruh Cuple Counseling ASI Pada Ibu Hamil Trisemester III Terhadap Pemberian ASI Eksklusif 2 Minggu Di Wilayah Kerja Puskesmas Kemuningsari Kabupaten Jember. Global Health Science, 3(3), 339-345.

Budiyanto, Arnika, asti dwi, \& Podo Yuwono. (2015). Hubungan Ketersediaan Fasilitas Penunjang Terhadap KEBERHASILANeberhasilan Ppemberian ASI Ekslusif Pada Ibu Yang Bekerja Sebagai Tenaga Kesehatan. 11(1), 6-18.

Desmawati, Agustina, \& Kusumastuti, R. D. (2020). Edukasi Ibu Menyusui Dengan Asi Eksklusif Melalui Komunikasi Interpersonal Di Wilayah Kerja Pamulang. Jurnal Pengabdian Masyarakat Kesehatan, 6(1), 17-22. https://doi.org/10.33023/jpm.v6i1.543

Hardhana, B., Siswanti, T., Sibuea, F., Widiantini, W., Susanti, M. I., Pangribowo, S., Aprianda, R., Indah, S., Mardina, R., Sakti, E. S., Wahyudi, T., Habibi, H. A., Sari, D. M., Sigit, B. B., Maslinda, H., \& Maula, R. (2018). DATA DAN INFORMASI PROFIL KESEHATAN INDONESIA.

Maita, L., \& Shalihah, N. imatu. (2015). Faktor-Faktor Yang Menyebabkan Pemberian Kolostrum Pada Ibu Nifas Di Ruang Camar I Rsud Arifin Achmad Provinsi Riau. Jurnal Maternity and Neonatal, 1(6), 254-261. marzali amri. (n.d.). Menulis Kajian Literatur.

Merdhika, W. A. R., Mardji, \& Devi, M. (2014). Pengaruh Penyuluhan ASI Eksklusif terhadap Pengetahuan Ibu tentang ASI Eksklusif dan Sikap Ibu Menyusui di Kecamatan Kanigoro Kabupaten Blitar. Teknologi Dan Kejuruan, 37(1), 65-72.

Nerita Awanda Putri. (2019). Pengaruh penyuluhan dengan media lembar balik ( flip chart) terhadap pengetahuan dan sikap ibu hamil tentang asi eksklusif di puskesmas tuban kabupaten tuban. In Universitas Muhammadiyah Surakarta (pp. 1-25).

Nishimura, H., Krupp, K., Gowda, S., Srinivas, V., Arun, A., \& Madhivanan, P. (2018). Determinants of exclusive breastfeeding in rural South India. International Breastfeeding Journal, 13(1), 1-7. https://doi.org/10.1186/s13006-018-0178-5

Rostina Afrida Pohan. (2020). Hubungan pengetahuan ibu menyusui tentang asi ekslusif dengan pemberian asi ekslusif di desa sei serindan kota tanjungbalai tahun 2019 rostina afrida pohan dosen tetap stikes sakinah husada. Jurnal Ilmiah Maksitek, 5(1), 25-31.

Sari, T. W., Wulandari, F. S., Hidayat, M. H., Amelia, N., Nasution, S., \& Yuriati, Y. (2018). Perbedaan Pengetahuan Ibu Sebelum dan Sesudah Diberikan Penyuluhan Tentang ASI Eksklusif di Wilayah Kerja Puskesmas Sidomulyo Rawat Inap Kota Pekanbaru 2018. Collaborative Medical Journal, 1(2), $58-65$.

Warnelis, E. (2018). Hubungan Pemberian ASI Eksklusif dan Perawatan Anak Usia 6-24 Bulan dengan Kejadian Diare di Puskesmas Pulo Brayan Medan Tahun 2017.

Widyawati, Sigit ambar, D. (2020). Peningkatan Pengetahuan Ibu Hamil Dan Menyusui Melalui Pengembangan Model Dan Media Animasi Pemberian Asi Ekslusif Pada Bayi. Jurnal Ilmiah Permas, 10(1), 103-108. http://journal.stikeskendal.ac.id/index.php/PSKM/article/view/622 
Yessy Dwi Wahani. (2017). Pengaruh Penyuluhan Melalui Media Leaflet Terhadap Pengetahuan Ibu Hamil Tentang ASI Eksklusif Di Desa Ngasinan Kecamatan Padangan Bojonegoro (Vol. 7, Issue 1).

Yustianingrum, L. N., \& Adriani, M. (2017). Perbedaan Status Gizi dan Penyakit Infeksi pada Anak Baduta yang Diberi ASI Eksklusif dan Non ASI Eksklusif The Differences of Nutritional Status and Infection Disease in Exclusive Breastfeed and Non Exclusive Breastfeed Toddlers. Research Study, 1(4), 415423. https://doi.org/10.20473/amnt.v1.i4.2017.415-423

Zulaikha, F., \& Ramadhani, L. (2017). Faktor-Faktor Penerapan Asi Eksklusif Di Samarinda. Dunia Keperawatan, 5(2), 83. https://doi.org/10.20527/dk.v5i2.4111 